\title{
Early-life risk factors for breast cancer - prospective follow-up in the Northern Finland Birth Cohort 1966
}

Anniina Tastula $^{1,2}$, Arja Jukkola ${ }^{3,4}$, Anni-Emilia Alakokkare ${ }^{1,2}$, Tanja Nordström ${ }^{1,2,5}$, Sanna Eteläinen $^{6,7}$, Peeter Karihtala ${ }^{8}$, Jouko Miettunen ${ }^{1,2}$

${ }^{1}$ Center for Life Course Health Research, University of Oulu, Oulu, Finland

${ }^{2}$ Medical Research Center Oulu, Oulu University Hospital and University of Oulu, Oulu, Finland

${ }^{3}$ Department of Oncology of Medicine and Radiotherapy, Tampere University Hospital, Tampere, Finland

${ }^{4}$ Tampere Cancer Center, Faculty of Medicine and Health Technology, University of Tampere, Tampere, Finland

${ }^{5}$ Infrastructure for Population Studies, Faculty of Medicine, University of Oulu, Oulu, Finland

${ }^{6}$ Department of Obstetrics and Gynaecology, Oulu University Hospital, Oulu, Finland ${ }^{7}$ PEDEGO Research Unit, University of Oulu, Oulu, Finland

${ }^{8}$ Helsinki University Hospital Comprehensive Cancer Center and University of Helsinki, Helsinki, Finland

Running title: Early-life risk factors for breast cancer.

Keywords: breast cancer, socioeconomic, early-life, residency, education

Corresponding author: Anniina Tastula, MD, Center for Life Course Health Research, P.O. Box 5000, 90014 University of Oulu, Oulu, Finland, anniina.tastula@ student.oulu.fi

The authors declare no potential conflicts of interest.

Word count: text 3334, abstract 250. The number of figures: 1, the number of tables: 3 . 


\section{Abstract}

Background: While some risk factors for breast cancer have been confirmed, less is known about the role of early biological and social risk factors for breast cancer in adult life.

Methods: In a prospective follow-up in the Northern Finland Birth Cohort 1966 consisting of 5308 women, 120 breast cancers were reported via national registers by the end of 2018 . Early risk factors were examined with univariate and multivariate analyses using Cox regression analysis. The main results are reported with hazard ratios (HR) and their $95 \%$ confidence intervals $(\mathrm{CI})$.

Results: In the multivariate-adjusted models, women whose mothers lived in urban areas (HR 1.68; $95 \%$ CI, 1.13-2.51) during pregnancy, were low-educated (HR 2.40; $95 \%$ CI, 1.30-4.45) and had been diagnosed with breast cancer (HR 1.97; $95 \%$ CI, 1.09-3.58), had a higher risk for breast cancer in adult life. Lower BMI at the age of 14 associated nonsignificantly with the risk of breast cancer (Mann-Whitney $U$ test, $P=0.087$ ). No association between birth size and breast cancer risk in adult life was found.

Conclusions: Early-life residence and socioeconomical conditions may have an impact on developing breast cancer in women in adult life. All breast cancer cases of this study were relatively young and most of them are assumed to be premenopausal.

Impact: This study is one of a few prospective birth cohort studies to examine early-life socioeconomic factors and breast cancer risk in adult life. This study is limited due to small number of cases. 


\section{Introduction}

Age, genetic and reproductive factors have a significant role in predicting breast cancer risk. The number of menstrual cycles during a woman's lifetime (age of menarche, age of first pregnancy, parity and onset of natural menopause) is strongly connected to higher risk of both premenopausal and postmenopausal breast cancer $(1,2)$. Of the early factors, some studies have shown a positive connection between birth length (3-7) and birth weight $(3,6,7)$ and risk of breast cancer. The connection between birth weight and risk of breast cancer has been found particularly among premenopausal women $(8,9)$ but this has not been observed in all studies $(5,10)$. Overweight before puberty and adolescence is associated with lower risk of premenopausal breast cancer (11-13). Along with antenatal period, the time-period between menarche and the first delivery of a child may have a strong impact on developing breast cancer. Physical activity during early-life, especially between menarche and the first pregnancy, has been considered as a protective factor for breast cancer $(14,15)$. Several epidemiological studies have stated that smoking during youth and before the first delivery of a child is strongly connected with increased risk of breast cancer (16-18). Alcohol consumption, especially before the first birth, has been associated with higher breast cancer risk $(19,20)$ According to previous studies, the association between maternal smoking and breast cancer in offspring is inconsistent $(21,22)$.

Higher education level has been associated with higher incidence of breast cancer which may be explained by reproductive factors such as giving birth fewer times and more frequent use of hormone therapy and alcohol $(23,24)$. Only a few studies have addressed the impact of individuals' early-life socioeconomic backgrounds, for example via parental education and occupation characteristics, on breast cancer risk in offspring in adult life $(25,26)$. Although multiple risk factors for breast cancer have been determined, the role of antenatal period and birth in breast cancer in adult life is less studied. Our aim was to investigate possible socioeconomic and biological early-life risk factors for breast cancer in a unique prospective 52-year-long birth cohort study.

\section{Materials and Methods}

\section{Study design and population}

The Northern Finland Birth Cohort 1966 (NFBC1966) is a population-based epidemiologic study of people who were expected to give birth in the northernmost provinces of Finland 
during 1966. A total of 12527 children were born in the northernmost provinces during 1966 and NFBC1966 represented $96.3 \%$ of all births in the area. Initially, the purpose of this birth cohort study was to research risk factors leading to preterm birth and intrauterine growth retardation. (27). Acquisition of the data was initiated during pregnancies by midwives in local antenatal clinics in 1965 . The questionnaire was filled in from the 24th to 28th gestational week or if not possible then, later during the pregnancy or after delivery $(10.1 \%$ of mothers). At the age of 14, the information of health, lifestyle habits, socioeconomical status and situation of parents was collected using postal questionnaires (coverage $93.6 \%$ of the target population). The postal questionnaire was first sent to the children and then if they did not respond to their parents. If neither of them responded, the same questionnaire was sent to the regional school offices and to the school health nurses.

Reported breast cancer cases were collected from the Care Register for Health Centre (CRHC) administered by the National Institute for Health and Welfare (28) and registers of the Social Insurance Institution of Finland and Finnish Center of Pensions based on the International Classification of Diseases (ICD-10), where invasive breast cancer cases (C50.0 - C50.9) were included in the analysis (29). CRHC is generally known to be suitable for research purposes (30), and, in our study, it was used instead of the Finnish Cancer Registry because CRHC covered all the cases and with CRHC we were able to get a longer follow-up (until the end of 2018), while the cancer data received from Finnish Cancer Registry ended by the end of 2013. Parental cancers were reported by the CRHC and Finnish Center of Pensions. The National Digital and Population Data Services Agency reported the data regarding emigration and cause of deaths by 1 May 2017 and individuals' childbearing history by 1 June 2016 (31). All information from national registers was linked to cohort data using personal identification numbers. The NFBC1966 study has been approved by the Ethical Committee of the Northern Ostrobothnia hospital district.

We restricted the study population to women who have been alive and living in Finland at the age of 25. A detailed exclusion process is presented in Figure 1. As a result, 5308 women were included in the final study. The follow-up time started from $25^{\text {th }}$ birthday and ended at death, emigration, breast cancer diagnosis or the end of the follow-up period on 31 December 2018, depending on whichever came first. Overall, the maximum prospective follow-up time was 28 years. 


\section{Risk factor assessments}

In this study, we focused on risk factors occurring in an individual's early life. The analysis included variables expressing socioeconomic status (SES) of an individual's parents such as mother's marital status (married, unmarried/divorced/widow), mother's education level (low 0-4 years, intermediate 5-8 years, high 9 years or more) (32), mother's occupation status (caregiver etc., manager or small business owner, worker, farmer or farmer's spouse), father's occupation status (no occupation/worker/farmer or farmer's spouse, manager or small business owner), mother's place of residence (urban, rural), parent's connections to farming (farmer or farmer's spouse, no connection to farming), and ownership of farm animals (yes, no). Mother's mood during pregnancy (normal, depressed), smoking during pregnancy (never-smoked, smoked daily during 12 months before the pregnancy but ended, continued during pregnancy) were also collected.

Maternal malignancies (no malignancies, maternal malignancies other than breast cancer, maternal breast cancer) and paternal malignancies (yes, no) were reported by the national registers described above. Paternal and maternal age at the time of birth (continuous), maternal height (continuous), maternal BMI before pregnancy (continuous) and birth characteristics of an individual were also explored. Instead of birth weight and birth height, we examined birth sizes using standard deviations $\left(\mathrm{SD}^{\mathrm{c}}\right)$ of national population-based fetal growth standards which consider sex, weight, length, gestational age and plurality of pregnancy (33).

From the questionnaire at adolescence (age of 14) we included the following variables: individual's body mass index (BMI) (continuous), smoking (never-smoked or tried once, smoked twice or more often), drinking (never or once binge drinking, binge drinking twice or more often) and physical activity (once a week, less frequently than once a week), mother's situation (working full-time outside of home, housewife or unemployed/part-time/temporary work/sick leave/pension) and father's situation (working full-time outside of home, unemployed/sick leave/student/pension).

\section{Statistical analysis}

All categorical variables were reviewed using crosstabulation analysis with unadjusted relative risk ratios (RRs) and $95 \%$ confidence intervals (CIs). Continuous variables were explored by comparing means and by using the Mann-Whitney U-test after testing normality with visual inspection of histograms, skewness and kurtosis's z-values and the Shapiro-Wilk 
test where none of the variables meet the criteria for normal distribution when stratified by status of breast cancer. The adjustment factors used in the multivariate analyses were decided based on previous studies addressed in the Introduction. Multivariate analyses were conducted using a series of Cox's proportional hazard models (with Hazard Ratios (HR), and 95\% CIs), where in model 1 we focused on factors occurring during pregnancy and birth and in model 2 we included also risk factors of individuals in later life. Model 1 included early maternal and birth characteristics (maternal malignancies, mother's place of residence and mother's education level, adjusted SD-scores for birth weight and adjusted SD-scores for birth height of an individual). In model 2 we included individuals' characteristics (smoking habits, drinking habits, physical activity, individuals' BMI) at the age of 14 and individuals' parity at the age of 24 (nulliparous, parous) (34). Level of statistical significance was set to $P$ $<0.05$ and all tests were two-tailed. With the current sample size and assuming proportions $33 \% / 67 \%$ in dichotomized variable, the minimum detectable hazard ratio is 1.72 with an $80 \%$ power and 5\% alpha level. Data modifying and statistical analyses were performed using SPSS Statistics Software version 25.0 (IBM Corporation, Armonk, NY, USA).

\section{Results}

A total of 120 female breast cancers were reported based on the national registers after 140209 follow-up years, cumulative incidence being $2.4 \%$. The median age of onset of breast cancer was 47.8 years (range 28.7-52.1), therefore, most of the breast cancer cases are assumed to be premenopausal. 113 women died and 105 emigrated between ages 25 and 51, and therefore were censored from regression analyses. One woman was diagnosed with another cancer before breast cancer and she was included in the analyses (results were similar also without this case). Among the 120 women with breast cancer 27 (22.5\%) were diagnosed within the 10 years after the last pregnancy and $70(58,3 \%)$ were diagnosed later. None gave birth after the breast cancer diagnosis and $23(19.2 \%)$ women were nulliparous.

Unadjusted results are presented in Table 1, 2 and the first column in Table 3. Maternal breast cancer was a statistically significant risk for breast cancer of an individual (RR 2.10; $95 \%$ CI 1.22-3.61). Maternal malignancy other than breast cancer was marginally associated with increased risk in offspring (RR 1.50; $95 \%$ CI 0.98-2.32) but paternal malignancy was not associated with a risk for breast cancer in offspring (RR 0.87; $95 \% \mathrm{CI}, 0.57-1.34$ ). Women whose mothers lived in urban areas during their pregnancy had a higher risk for breast cancer in adult life compared to mothers who lived in rural areas (RR 1.53; $95 \%$ CI, 1.07-2.19). 
Offspring of mothers with a of low-level education had also higher risk for breast cancer, however, after rounding to 2 decimals, the association was not statistically significant (RR 1.67; $95 \%$ CI, 1.00-2.80). Other variables were not statistically significant for risk of breast cancer. None of the continuous variables (data presented in Table 2) were significantly associated with breast cancer risk in adult life. Women diagnosed with breast cancer in adult life were thinner at the age of $14(P=0.087$, Mann-Whitney $U$ test $)$ but statistical significance was not reached.

Mother's residency in urban areas in model 1 (HR 1.77; 95\% CI 1.21-2.57) and in model 2 (HR 1.68; 95\% CI 1.13-2.51) and mother's low education in model 1 (HR 2.09; 95\% CI 1.22-3.55) and in model 2 (HR 2.40; 95\% CI 1.30-4.45) were statistically significant after adjustment of maternal factors, birth characteristics or factors in adolescence and early adult life (Table 3). Maternal breast cancer was statistically significant in both models (HR 2.22; $95 \%$ CI 1.28-3.87 and HR 1.97; 95 \% CI 1.09-3.58, respectively). Maternal malignancies other than breast cancer did not have an association in either of the two models. None of the confounders included in Model 1 or Model 2 were statistically significant.

\section{Discussion}

In the 52-year-long prospective birth cohort study of 5308 women born in the northernmost provinces of Finland in 1966, we found that certain early-life socioeconomic factors, such as maternal place of residence during pregnancy and maternal education level, may have an indirect role in the risk for breast cancer in offspring regardless of history of maternal malignancies and multiple biological factors such as birth characteristics and parity. Consistent with prior evidence (35), history of breast cancer in first-degree family (in our study, maternal) was associated with a twofold increase risk for breast cancer in offspring.

From a socioeconomic perspective, comparing cohort studies from different areas and different periods of time may be problematic and, moreover, SES definitions are difficult to harmonize. In our study, daughters whose mothers were low educated (0-4 years) had higher incidence of breast cancer in adult life, even in multivariate models, but paternal occupation did not have an influence on breast cancer incidence in offspring. The father's education was not available in the current study. Low maternal education has not previously been linked earlier to breast cancer risk. A case-control study reported a significant result for higher paternal education (OR 1.22; $95 \%$ CI 1.03-1.45), but the study included only 
postmenopausal breast cancer (36). Two other studies found no association between paternal occupation/employment and breast cancer incidence in offspring $(37,38)$. Pudrovska et al. reported a significant association between mother's higher education and breast cancer in offspring (HR 1.23; p < 0.05) (39), however, in a Scandinavian register-based study of perinatal characteristics in relation to breast cancer risk the effect of maternal education remained insignificant (4). Two studies have found an association between family income and increased breast cancer incidence in offspring $(39,40)$. Furthermore, in a study based on birth certificates, women with the highest SES at birth had higher risk of breast cancer in adulthood compared to those with the lowest SES (26). In addition, individuals with the highest SES in childhood were more likely to be diagnosed with breast cancer in adult life (HR 1.53; $95 \%$ CI 1.07-2.19) compared to the lowest SES in an ambidirectional study (41). At least two birth cohort studies have researched if early-life socioeconomical status has effect on mammographic breast density, a well-known risk factor for breast cancer, but the results are inconsistent $(42,43)$.

Higher breast cancer incidence for daughters with low-educated mothers could be explained by an accumulation model where lower SES in early life leads to more intense and/or longerlasting exposures during a lifespan (44). For example, lower SES during early life may have an association with earlier pubertal development, thus indirectly increasing the risk of breast cancer in adulthood $(45,46)$. However, puberty timing of our study group was not known, and moreover, no association between family SES and menarche was found in a survey and register data of randomly selected subsample of Finns born between 1966 and 1980 (47). Lower childhood SES may lead to poorer health and higher risk of cancer in adult life via quality of maternal nutrition, dietary habits during childhood and low-level physical activity (48), but physical activity was not a significant confounder in our study. On the other hand, parental education level is a decent predictor for children's attainments $(39,49)$ and the higher-educated have a tendency to conduct reproductive behavior favorable for risk of breast cancer $(23,50)$

In our study, daughters of mothers who lived in urban areas during pregnancy were more likely to be diagnosed with breast cancer in adult life compared to those whose mothers lived in rural areas. However, we did not have data on individuals' residency throughout childhood. Some studies have observed that breast cancer incidence is higher in urban areas $(51,52)$. To our knowledge, only two studies have investigated the relation between residency in early life and subsequent breast cancer incidence $(53,54)$. A study regarding the 
possible connection between fish consumption and adolescence residency and subsequent breast cancer incidence did not reveal a strong connection between residency during adolescence among women who were born in Iceland between 1908-1935, although there was an inverse association between hormone receptor-negative tumors and living in coastal areas from birth to the age of 20 years (HR 0.78; 95\% CI, 0.61-0.99), which might be explained by high-frequency fish consumption (53). In a prospective French cohort consisting of 75889 women (aged 38-66) born in urban areas, a significantly higher risk for breast cancer in adult life was seen compared to women who were born in rural areas (adjusted HR 1.07; $95 \%$ CI 1.01-1.14). In the French study, connection between residency at birth and breast cancer in adult life was stronger than residency in adult life, which could suggest that environmental factors and exposures in early life have an important role in determining a risk profile, regardless of residency in adulthood (54). Our results are consistent with the study conducted by Binachon et al., however, neither of the previous studies were able to prospectively follow individuals from birth.

Our results of lower BMI at the age of 14 and increased breast cancer incidence are consistent with previous studies regarding of premenopausal breast cancer (11-13) although statistical significance was not reached in our material. The phenomenon has been explained by different possible pathways. One theory is an inverse link between weight and density of breast tissue developing during adolescence (55) since convincing evidence shows mammographic density is a high risk factor for breast cancer (56). Secondly, greater adipose tissue in puberty has been shown to have a connection to lower peak height growth, which also could indirectly decrease the incidence of breast cancer (13). Thirdly, childhood BMI is inversely associated with cancer-promoting insulin-like growth factor 1 hormone levels in adulthood $(57,58)$ and in addition, weight may inversely affect sex-hormone levels such as total estrogen levels before menopause but evidence on the connection between BMI and different sex hormone levels is inconsistent (59). Unlike previous studies, we did not find a connection between maternal and antenatal anthropometric features and breast cancer incidence in adult life. Whether this is due to inclusion of only relatively young women in our study remains unclear. Individuals' birth sizes were moderately smaller than means of national standards, however these references were constructed based on birth register data of infants born in 1996-2008 (33).

Our study has multiple strengths. First, over 50-year-old birth-cohorts are rare, and being a prospective study, the data reported can be assumed to be uninfluenced by later breast cancer 
diagnosis. For example, when conducting a questionnaire from the past, individuals who have been diagnosed with cancer or some other disease might report factors affecting risk of the outcome more specifically causing recall bias. Secondly, the amount of reported cancer cases is highly reliable because of national mandatory reporting. Thirdly, the population-based nature of the sample increases the heterogeneity of the study population. In addition, almost none of the previous studies have adjusted antenatal anthropometrics with plurality and gestational age, although some have used the Ponderal Index $\left(\mathrm{kg} / \mathrm{m}^{3}\right)(3,4,6)$.

Our study has several limitations. The homogeneity in Northern Finland population during the 1960s may have impact on the variance in SES. Due to relative low number of breast cancer cases, we were not able to study rare risk factors. Some of categorical variables had to be combined. Since the biological subtype of breast cancer may have an impact on early-life risk factors, the lack of knowledge of siblings' breast cancer history and the presence of possible breast cancer predisposing mutations such as BRCA1 and BRCA2 makes it difficult to differentiate the strength of possible genetic vulnerability from environmental factors. Furthermore, since the breast cancer cases in our material are relatively young and some of them have been diagnosed couple of years after individual's own pregnancy, there may have an overrepresentation of triple-negative breast cancers, which can be considered as a potential confounder in our study. We adjusted for several early-risk factors, but we were not able to adjust for some factors, such as age at menarche, use of hormonal therapy, and adulthood SES, weight, height, alcohol and tobacco use. Menopausal status was also not known. Answers on the 14-year questionnaire about tobacco and alcohol use may also include bias.

In conclusion, early-life factors such as place of residence and maternal SES may have an indirect role related to the risk of breast cancer of relatively early onset regardless of history of maternal breast cancer or other malignancies. Since these results apply especially to relatively young women, more data aggregated prospectively throughout lifetime is needed. 


\section{Acknowledgments}

A. Tastula's contribution to the study has been supported by the Health and Biosciences Doctoral Programme, HBS-DP (University of Oulu) and J. Miettunen has received a grant from the Juho Vainio Foundation. The authors thank all the individuals who have participated in NFBC1966 and research personnel who have been responsible for data acquisition. Data is available from the NFBC project center based on criteria for accessing confidential data. 


\section{References}

1. Continuous Update Project Report. Food: Nutrition, Physical Activity, and the Prevention of Breast Cancer. 2018. Available from: www.dietandcancerreport.org.

2. Collaborative Group on Hormonal Factors in Breast Cancer. Menarche, menopause, and breast cancer risk: individual participant meta-analysis, including 118964 women with breast cancer from 117 epidemiological studies. Lancet Oncol 2012;13:1141-51.

3. Schmid D, Willett WC, Ding M, Michels KB. Maternal and Infant Anthropometric Characteristics and Breast Cancer Incidence in the Daughter. Sci Rep-UK 2020;10:2550.

4. Troisi R, Grotmol T, Jacobsen J, Tretli S, Sørensen HT, Gissler M, et al. Perinatal characteristics and breast cancer risk in daughters: a Scandinavian population-based study. J Dev Orig Hlth Dis $2013 ; 4: 35-41$.

5. Sandvei M, Lagiou P, Romundstad PR, Trichopoulos D, Vatten LJ. Size at birth and risk of breast cancer: update from a prospective population-based study. Eur J Epidemiol 2015;30:485-92.

6. Silva IdS, Stavola BD, McCormack V. Birth Size and Breast Cancer Risk: Re-analysis of Individual Participant Data from 32 Studies. PLoS Med 2008;5:e193.

7. Xue F, Michels KB. Intrauterine factors and risk of breast cancer: a systematic review and metaanalysis of current evidence. Lancet Oncol 2007;8:1088-100.

8. Michels KB, Xue F, Terry KL, Willett WC. Longitudinal study of birthweight and the incidence of breast cancer in adulthood. Carcinogenesis 2006;27:2464-8.

9. Wu AH, McKean-Cowdin R, Tseng C. Birth weight and other prenatal factors and risk of breast cancer in Asian-Americans. Breast Cancer Res \& Tr 2011;130:917-25.

10. Andersen ZJ, Baker JL, Bihrmann K, Vejborg I, Sorensen TIA, Lynge E. Birth weight, childhood body mass index, and height in relation to mammographic density and breast cancer: a register-based cohort study. Breast Cancer Res 2014;16:R4.

11. Baer HJ, Colditz GA, Rosner B, Michels KB, Rich-Edwards JW, Hunter DJ, et al. Body fatness during childhood and adolescence and incidence of breast cancer in premenopausal women: a prospective cohort study. Breast Cancer Res 2005;7:R314-25.

12. Schoemaker MJ, Nichols HB, Wright LB, Brook MN, Jones ME, O'Brien KM, et al. Association of Body Mass Index and Age With Subsequent Breast Cancer Risk in Premenopausal Women. JAMA Oncol 2018;4:e181771.

13. Berkey CS. Adolescence and Breast Carcinoma Risk. JAMA-J Am Med Assoc 1999;282:718.

14. Liu Y, Tobias DK, Sturgeon KM, Rosner B, Malik V, Cespedes E, et al. Physical activity from menarche to first pregnancy and risk of breast cancer. Int J Cancer 2016;139:1223-30.

15. Maruti SS, Willett WC, Feskanich D, Rosner B, Colditz GA. A Prospective Study of Age-Specific Physical Activity and Premenopausal Breast Cancer. J Natl Cancer I 2008;100:728-37.

16. Bjerkaas E, Parajuli R, Weiderpass E, Engeland A, Maskarinec G, Selmer R, et al. Smoking duration before first childbirth: an emerging risk factor for breast cancer? Results from 302,865

Norwegian women. Cancer Cause Control 2013;24:1347-56. 
18. Gaudet MM, Carter BD, Brinton LA, Falk RT, Gram IT, Luo J, et al. Pooled analysis of active cigarette smoking and invasive breast cancer risk in 14 cohort studies. Int J Epidemiol 2017;46:88193.

19. Romieu I, Scoccianti C, Chajès V, de Batlle J, Biessy C, Dossus L, et al. Alcohol intake and breast cancer in the European prospective investigation into cancer and nutrition. Int $\mathrm{J}$ Cancer 2015;137:1921-30.

20. Liu Y, Colditz GA, Rosner B, Berkey CS, Collins LC, Schnitt SJ, et al. Alcohol Intake Between Menarche and First Pregnancy: A Prospective Study of Breast Cancer Risk. J Natl Cancer Inst 2013;105:1571-8.

21. White AJ, D'Aloisio AA, Nichols HB, DeRoo LA, Sandler DP. Breast cancer and exposure to tobacco smoke during potential windows of susceptibility. Cancer Cause Control 2017;28:667-75.

22. Strohsnitter WC, Noller KL, Titus-Ernstoff L, Troisi R, Hatch EE, Poole C, et al. Breast Cancer Incidence in Women Prenatally Exposed to Maternal Cigarette Smoke. Epidemiology 2005;16:342-5.

23. Braaten T, Weiderpass E, Kumle M, Adami H, Lund E. Education and risk of breast cancer in the Norwegian-Swedish women's lifestyle and health cohort study. Int J Cancer 2004;110:579-83.

24. Dong J, Qin L. Education level and breast cancer incidence: a meta-analysis of cohort studies. Menopause 2019;27:113-118.

25. Akinyemiju TF, Demb J, Izano MA, Rehkopf DH, Fang M, Hiatt RA, et al. The association of early life socioeconomic position on breast cancer incidence and mortality: a systematic review. Int $\mathbf{J}$ of Public Health 2018;63:787-97.

26. Stroup AM, Herget KA, Hanson HA, Reed DL, Butler JT, Henry KA, et al. Baby Boomers and Birth Certificates: Early-Life Socioeconomic Status and Cancer Risk in Adulthood. Cancer Epidem Biomar 2017;26:75-84.

27. Rantakallio P, Hartikainen-Sorri AL. The relationship between birth weight, smoking during pregnancy and maternal weight gain. Am J Epidemiol. 1981;113:590-5.

28. Care Register for Health Care. 2016 [latest update February 2019]. Available from: https://thl.fi/en/web/thlfi-en/statistics/information-on-statistics/register-descriptions/care-register-forhealth-care.

29. World Health Organization. International classification of diseases and related health problems. Geneva, Switzerland. 1992;10th rev., ICD-10.

30. Miettunen J, Suvisaari J, Haukka J, Isohanni M. Use of Register Data for Psychiatric Epidemiology in the Nordic Countries. Chichester, UK: John Wiley \& Sons, Ltd; 2011.

31. Digital and Population Data Serves Agency. 2020. Available from: https://dvv.fi/en/individuals.

32. Keskinen E. Parental psychosis, risk factors and protective factors for schizophrenia and other psychosis: the Northern Finland Birth Cohort 1966. Acta Universitatis Ouluensis. 2015. Available from http://jultika.oulu.fi/files/isbn9789526210483.pdf

33. Sankilampi U, Hannila M, Saari A, Gissler M, Dunkel L. New population-based references for birth weight, length, and head circumference in singletons and twins from 23 to 43 gestation weeks. Ann Med 2013;45:446-54. 
34. Lambertini M, Santoro L, Del Mastro L, Nguyen B, Livraghi L, Ugolini D, et al. Reproductive behaviors and risk of developing breast cancer according to tumor subtype: A systematic review and meta-analysis of epidemiological studies. Cancer Treat Rev 2016;49:65-76.

35. Collaborative Group on Hormonal Factors in Breast Cancer. Familial breast cancer: collaborative reanalysis of individual data from 52 epidemiological studies including 58209 women with breast cancer and 101986 women without the disease. Lancet (British edition). 2001;358:1389-99.

36. Titus-Ernstoff L, Egan KM, Newcomb PA, Ding J, Trentham-Dietz A, Greenberg ER, et al. Early Life Factors in Relation to Breast Cancer Risk in Postmenopausal Women. Cancer Epidem Biomar 2002;11:207.

37. de Kok IMCM, van Lenthe FJ, Avendano M, Louwman M, Coebergh JW, Mackenbach JP. Childhood social class and cancer incidence: Results of the globe study. Soc Sci Med 2008;66:11319.

38. Dirx JM, van den Brandt PA, Goldbohm RA, Lumey LH. Diet in Adolescence and the Risk of Breast Cancer: Results of the Netherlands Cohort Study. Cancer Cause Control 1999;10:189-99.

39. Pudrovska T, Anikputa B. The Role of Early-Life Socioeconomic Status in Breast Cancer Incidence and Mortality. J Aging Health 2012;24:323-44.

40. Lope V, García-Esquinas E, Pérez-Gómez B, Altzibar JM, Gracia-Lavedan E, Ederra M, et al. Perinatal and childhood factors and risk of breast cancer subtypes in adulthood. Cancer Epidemiol 2015;40:22-30.

41. van der Linden B, Courvoisier D, Cheval B, Sieber S, Bracke P, Guessous I, et al. Effect of childhood socioeconomic conditions on cancer onset in later life: an ambidirectional cohort study. Int J Public Health 2018;63:799-810.

42. Akinyemiju TF, Tehranifar P, Flom JD, Liao Y, Wei Y, Terry MB. Early life growth, socioeconomic status, and mammographic breast density in an urban US birth cohort. Ann Epidemiol 2016;26:540,545.e2.

43. Tehranifar P, Cohn BA, Flom JD, Protacio A, Cirillo P, Lumey LH, et al. Early life socioeconomic environment and mammographic breast density. BMC Cancer 2017;17:41.

44. Chen M, Zhu H, Du Y, Yang G. How does the social environment during life course embody in and influence the development of cancer? Int J Public Health 2018;63:811-21.

45. Hiatt RA, Stewart SL, Hoeft KS, Kushi LH, Windham GC, Biro FM, et al. Childhood Socioeconomic Position and Pubertal Onset in a Cohort of Multiethnic Girls: Implications for Breast Cancer. Cancer Epidem Biomar 2017;26:1714-21.

46. James-Todd T, Tehranifar P, Rich-Edwards J, Titievsky L, Terry MB. The Impact of Socioeconomic Status across Early Life on Age at Menarche Among a Racially Diverse Population of Girls. Ann Epidemiol 2010;20:836-42.

47. Acacio-Claro PJ, Koivusilta LK, Doku DT, Rimpelä AH. Timing of puberty and reserve capacity in adolescence as pathways to educational level in adulthood - a longitudinal study. Ann Hum Biol 2019;46:35-45.

48. Cohen S, Janicki-Deverts D, Chen E, Matthews KA. Childhood socioeconomic status and adult health. Ann NY Acad Sci 2010;1186:37-55. 
49. Haveman R, Wolfe B. The Determinants of Children's Attainments: A Review of Methods and Findings. J Econ Lit 1995;33:1829-78.

50. Menvielle G, Kunst AE, Gils CHV, Peeters PHM, Boshuizen H, Overvad K, et al. The contribution of risk factors to the higher incidence of invasive and in situ breast cancers in women with higher levels of education in the European prospective investigation into cancer and nutrition. Am J Epidemiol 2011;173:26.

51. Robert SA, Strombom I, Trentham-Dietz Amy, Hampton JM, McElroy JA, Newcomb PA, et al. Socioeconomic Risk Factors for Breast Cancer: Distinguishing Individual- and Community-Level Effects. Epidemiology 2004;15:442-50.

52. Moss JL, Liu B, Feuer EJ. Urban/Rural Differences in Breast and Cervical Cancer Incidence: The Mediating Roles of Socioeconomic Status and Provider Density. Women's Health Iss 2017;27:683-91.

53. Haraldsdottir A, Steingrimsdottir L, Valdimarsdottir UA, Aspelund T, Tryggvadottir L, Harris TB, et al. Early Life Residence, Fish Consumption, and Risk of Breast Cancer. Cancer Epidem Biomar 2017;26:346-54.

54. Binachon B, Dossus L, Danjou AM, Clavel-Chapelon F, Fervers B. Life in urban areas and breast cancer risk in the French E3N cohort. Eur J Epidemiol 2014;29:743-51.

55. Schoemaker MJ, Jones ME, Allen S, Hoare J, Ashworth A, Dowsett M, et al. Childhood body size and pubertal timing in relation to adult mammographic density phenotype. Breast Cancer Res 2017;19:13.

56. Boyd NF, Martin LJ, Yaffe MJ, Minkin S. Mammographic density and breast cancer risk: current understanding and future prospects. Breast cancer Res 2011;13:223.

57. Poole EM, Tworoger SS, Hankinson SE, Schernhammer ES, Pollak MN, Baer HJ. Body Size in Early Life and Adult Levels of Insulin-like Growth Factor 1 and Insulin-like Growth Factor Binding Protein 3. Am J Epidemiol 2011;174:642-51.

58. Schernhammer ES, Tworoger SS, Eliassen AH, Missmer SA, Holly JM, Pollak MN, et al. Body shape throughout life and correlations with IGFs and GH. Endocr-Relat Cancer 2007;14:721-32.

59. Key TJ, Appleby PN, Reeves GK, Travis RC, Alberg AJ, Barricarte A, et al. Sex hormones and risk of breast cancer in premenopausal women: a collaborative reanalysis of individual participant data from seven prospective studies. Lancet Oncol 2013;14:1009-19. 


\section{Tables}

Table 1. Crosstabulations and unadjusted risk ratios (RRs) for each variable.

\begin{tabular}{|c|c|c|c|}
\hline Variable & $\begin{array}{l}\text { Total } \\
\mathrm{n}=5308^{\mathrm{a}}\end{array}$ & $\begin{array}{l}\text { No. of breast cancer } \\
\text { cases } n=120(\%)\end{array}$ & $\begin{array}{l}\text { Unadjusted RR } \\
(95 \% \mathrm{Cl})\end{array}$ \\
\hline \multicolumn{4}{|l|}{ Mother's marital status } \\
\hline married & 5089 & $117(2.3)$ & ref \\
\hline unmarried/divorced/widow & 199 & $3(1.5)$ & $0.66(0.21-2.06)$ \\
\hline \multicolumn{4}{|l|}{ Mother's place of residence } \\
\hline rural & 3541 & $68(1.9)$ & ref \\
\hline urban & 1767 & $52(2.9)$ & $1.53(1.07-2.19)$ \\
\hline \multicolumn{4}{|l|}{ Mother's education } \\
\hline high ( 9 years or more) & 1795 & $39(2.2)$ & $1.01(0.68-1.50)$ \\
\hline intermediate ( $5-8$ years) & 2924 & $63(2.2)$ & ref \\
\hline low (4 years or less) & 499 & $18(3.6)$ & $1.67(1.00-2.80)$ \\
\hline \multicolumn{4}{|l|}{ Mother's occupation } \\
\hline caregiver etc. & 1740 & $38(2.2)$ & ref \\
\hline manager or small business owner & 667 & $16(2.4)$ & $1.10(0.62-1.96)$ \\
\hline worker & 1579 & $40(2.5)$ & $1.16(0.75-1.80)$ \\
\hline farmer or farmer's spouse & 1247 & $25(2.0)$ & $0.92(0.56-1.51)$ \\
\hline \multicolumn{4}{|l|}{ Father's occupation } \\
\hline manager or small business owner & 1237 & $29(2.3)$ & ref \\
\hline worker, farmer or no occupation & 3839 & $88(2.3)$ & $0.98(0.65-1.48)$ \\
\hline \multicolumn{4}{|l|}{ Is either of parent a farmer? } \\
\hline yes & 1338 & $25(1.9)$ & ref \\
\hline no & 3728 & $91(2.4)$ & $1.31(0.84-2.03)$ \\
\hline \multicolumn{4}{|l|}{ Ownership of farm animals (cows/pigs/sheep/chickens) } \\
\hline yes & 1518 & $28(1.8)$ & ref \\
\hline no & 3790 & $92(2.4)$ & $1.32(0.87-2.00)$ \\
\hline \multicolumn{4}{|l|}{ Mother's mood during pregnancy } \\
\hline normal & 4457 & $101(2.3)$ & ref \\
\hline depressed & 725 & $18(2.5)$ & $1.10(0.67-1.80)$ \\
\hline \multicolumn{4}{|l|}{ Was the pregnancy planned/hoped? } \\
\hline appropriate time & 3290 & $72(2.2)$ & ref \\
\hline should have happened later & 1276 & $34(2.7)$ & $1.22(0.81-1.82)$ \\
\hline not at all & 606 & $13(2.1)$ & $0.98(0.55-1.76)$ \\
\hline \multicolumn{4}{|l|}{ Maternal smoking } \\
\hline never-smoked & 4120 & $94(2.3)$ & ref \\
\hline smoked before pregnancy but stopped & 343 & $6(1.7)$ & $0.75(0.33-1.69)$ \\
\hline smoked during pregnancy & 670 & $18(2.7)$ & $1.18(0.72-1.94)$ \\
\hline \multicolumn{4}{|l|}{ Maternal malignancies } \\
\hline breast cancer & 368 & $15(4.1)$ & $2.10(1.22-3.61)$ \\
\hline other malignance than breast cancer & 924 & $27(2.9)$ & $1.50(0.98-2.32)$ \\
\hline no malignancies & 4016 & $78(1.9)$ & ref \\
\hline \multicolumn{4}{|l|}{ Paternal malignancy } \\
\hline no & 4030 & $94(2.3)$ & ref \\
\hline yes & 1278 & $26(2.0)$ & $0.87(0.57-1.34)$ \\
\hline \multicolumn{4}{|l|}{ Binge drinking at the age of 14} \\
\hline never or 1 time & 4126 & $93(2.3)$ & ref \\
\hline twice or more often & 839 & $21(2.5)$ & $1.11(0.70-1.77)$ \\
\hline \multicolumn{4}{|l|}{ Smoking at the age of 14} \\
\hline never or 1 time & 3001 & $70(2.3)$ & ref \\
\hline twice or more often & 1979 & $44(2.2)$ & $0.95(0.66-1.38)$ \\
\hline \multicolumn{4}{|l|}{ Physical activity at the age of 14} \\
\hline at least once a week & 3416 & $80(2.3)$ & ref \\
\hline less frequently than once a week & 1498 & $34(2.3)$ & $0.97(0.65-1.44)$ \\
\hline \multicolumn{4}{|l|}{ Mother's situation at the age of 14} \\
\hline working full-time outside of home & 1694 & $64(2.4)$ & ref \\
\hline housewife & 2682 & $39(2.3)$ & $0.97(0.65-1.43)$ \\
\hline unemployed, part-time/temporary work, sick leave or pension & 511 & $9(1.8)$ & $0.74(0.37-1.47)$ \\
\hline \multicolumn{4}{|l|}{ Father's situation at the age of 14} \\
\hline working full-time outside of home & 3797 & $83(2.2)$ & ref \\
\hline unemployed, sick leave, or student or pension & 770 & $22(2.9)$ & $1.31(0.82-2.08)$ \\
\hline
\end{tabular}


Table 2. Characteristics of continuous variables.

\begin{tabular}{|c|c|c|c|c|c|c|c|}
\hline \multirow[b]{2}{*}{ Variable } & \multirow{2}{*}{$\begin{array}{l}\text { Total N } \\
=5308 \\
\text { Total } \\
(\mathrm{N})\end{array}$} & \multicolumn{2}{|c|}{ Breast cancer $(n=120)$} & \multicolumn{2}{|c|}{ Control group $(n=5188)$} & \multicolumn{2}{|c|}{ Mann-Whitney U } \\
\hline & & $\begin{array}{l}\text { Cases } \\
\text { (n) }\end{array}$ & Mean (SD) & $\begin{array}{l}\text { Cases } \\
\text { (n) }\end{array}$ & Mean (SD) & $\bar{Z}$ & $\begin{array}{l}\text { P-value (2- } \\
\text { tailed) }\end{array}$ \\
\hline Maternal age (years) & 5307 & 120 & $27.8(6.25)$ & 5187 & $27.9(6.65)$ & -0.009 & 0.99 \\
\hline Paternal age (years) & 5042 & 117 & $30.6(7.42)$ & 4925 & $31.1(7.22)$ & -0.77 & 0.44 \\
\hline Maternal height (m) & 5045 & 112 & $1.60(0.060)$ & 4933 & $1.60(0.055)$ & -0.54 & 0.59 \\
\hline $\begin{array}{l}\text { Maternal pre-pregnancy } \\
\operatorname{BMI}^{\mathrm{C}}\left(\mathrm{kg} / \mathrm{m}^{2}\right)\end{array}$ & 4868 & 107 & $23.0(3.34)$ & 4761 & $23.1(3.24)$ & -0.47 & 0.64 \\
\hline Birthweight (g) & 5308 & 120 & $3390(593)$ & 5188 & $3400(549)$ & -0.56 & 0.57 \\
\hline$S^{c}$-correction ${ }^{a}$ & 5027 & 117 & $-0.47(1.35)$ & 4910 & $-0.38(1.25)$ & -1.13 & 0.26 \\
\hline Birth length (cm) & 5265 & 120 & $49.7(2.16)$ & 5145 & $49.8(2.45)$ & -0.55 & 0.59 \\
\hline$S D^{c}$-correction ${ }^{b}$ & 5027 & 117 & $-0.32(1.19)$ & 4910 & $-0.46(2.90)$ & -1.05 & 0.30 \\
\hline $\begin{array}{l}\mathrm{BMI}^{\mathrm{C}} \text { at the age of } 14 \\
\left(\mathrm{~kg} / \mathrm{m}^{2}\right)\end{array}$ & 4661 & 110 & $18.9(2.02)$ & 4551 & $19.4(2.51)$ & -1.71 & 0.087 \\
\hline
\end{tabular}

${ }^{a}$ Standard deviations $\left(\mathrm{SD}^{\mathrm{c}}\right)$ of national population-based fetal growth standards which consider sex, weight, length, gestational age and plurality of pregnancy (33)

${ }^{\mathrm{B}} \mathrm{BMI}=$ body mass index 


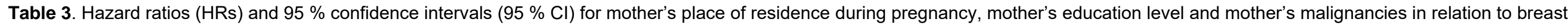
cancer in offspring.

\begin{tabular}{|c|c|c|c|c|}
\hline & Person-years & Unadjusted model $\left(B C^{C} 120\right)$ & Model $1^{a}\left(B C^{c} 117\right)$ & Model $2^{b}\left(B C^{c} 106\right)$ \\
\hline$\overline{\text { Adjustments }}$ & & & $\begin{array}{l}\text { 1. maternal place of residence } \\
\text { 2. maternal education } \\
\text { 3. maternal malignancies } \\
\text { 4. individual's birth length }\left(S D^{c}\right) \\
\text { 5. individual's birth weight }\left(S D^{c}\right)\end{array}$ & $\begin{array}{l}\text { 1. model } 1 \\
\text { 2. individual's smoking at the age of } 14 \\
\text { 3. individual's drinking at the age of } 14 \\
\text { 4. individual's physical activity at the age of } 14 \\
\text { 5. individual's BMI }{ }^{d} \text { at the age of } 14 \\
\text { 6. individual's parity at the age of } 24\end{array}$ \\
\hline Risk factors & $\mathbf{n}$ & & $\mathrm{HR}(95 \% \mathrm{Cl})$ & $\mathrm{HR}(95 \% \mathrm{Cl})$ \\
\hline $\begin{array}{l}\text { mother's place of residence } \\
\text { rural } \\
\text { urban }\end{array}$ & $\begin{array}{l}93,855 \\
46,354\end{array}$ & $\begin{array}{l}1.00 \text { (reference) } \\
1.56(1.09-2.24)\end{array}$ & $\begin{array}{l}1.00 \text { (reference) } \\
1.77(1.21-2.57)\end{array}$ & $\begin{array}{l}1.00 \text { (reference) } \\
1.68(1.13-2.51)\end{array}$ \\
\hline $\begin{array}{l}\text { mother's education level } \\
\text { low }<4 \text { years } \\
\text { intermediate } 5-8 \text { years } \\
\text { high } \geq 9 \text { years } \\
\text { mother's malignancies }\end{array}$ & $\begin{array}{l}13,224 \\
77,838 \\
46,774\end{array}$ & $\begin{array}{l}1.69(1.00-2.85) \\
1.00 \text { (reference) } \\
1.04(0.70-1.55)\end{array}$ & $\begin{array}{l}2.09(1.22-3.55) \\
1.00 \text { (reference) } \\
0.94(0.63-1.42)\end{array}$ & $\begin{array}{l}2.40(1.30-4.45) \\
1.00 \text { (reference) } \\
1.17(0.76-1.80)\end{array}$ \\
\hline $\begin{array}{l}\text { no cancer } \\
\text { other cancer than } \mathrm{BC}^{\mathrm{c}} \\
\text { breast cancer }\end{array}$ & $\begin{array}{l}106,352 \\
24,249 \\
9607\end{array}$ & $\begin{array}{l}1.00 \text { (reference) } \\
1.53(0.99-2.37) \\
2.17(1.25-3.76)\end{array}$ & $\begin{array}{l}1.00 \text { (reference) } \\
1.46(0.93-2.29) \\
2.22(1.28-3.87)\end{array}$ & $\begin{array}{l}1.00 \text { (reference) } \\
1.27(0.78-2.09) \\
1.97(1.09-3.58)\end{array}$ \\
\hline
\end{tabular}

${ }^{\text {a }}$ Model 1 adjustment: birth weight (SD-score, continuous), birth length (SD-score, continuous)

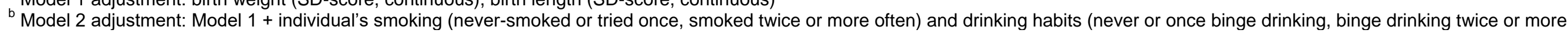

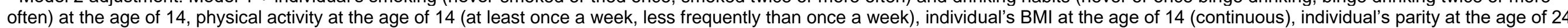
(nulliparous, parous).

${ }^{c} \mathrm{BC}=$ breast cancer

${ }^{\mathrm{d}} \mathrm{BMI}=$ body mass index 


\section{Figure Legends}

Figure 1. Excluding process for individuals based on specific criteria.

\section{Figures}




\section{Figure 1}

Baseline enrollment of NFBC1966 $(\mathrm{N}=12135)$

1. males $(\mathrm{N}=6213)$ \& sex was not defined $(2)$
2. malignancies before turning 14 years $(=12$
women)
3. death by the age of $25(=134$ women $)$
4. moved abroad by the age of $25(=434$ women $)$
5. gynecology cancers ( 32 women), including 2
women with both breast \& gynecology cancers
Individuals included for analysis $(\mathrm{N}=5308)$

